\title{
Estado, capitalismo y comunidades rurales. Procesos de producción de desigualdades sociales en Campeche, México
}

\author{
UBALDO DZIB CAN
}

\begin{abstract}
Exploro los procesos de formación de ciertos grupos sociales, el Estado y el capital en una zona rural del Sur de Campeche. Argumento que el Estado no ha sido el creador primo de la vida social de los sujetos, sino parte de los procesos de ésta, en los que las formas y categorías del Estado han sido producidas de manera desigual por los grupos y clases para fijar las asimetrías creadas entre ellos. En Campeche, el Estado es el resultado institucional de la producción de categorías como nativos y colonos, mayas y mestizos, patrones y clientes, como grupos jerarquizados. Por lo tanto, el Estado no debe ser el punto de partida del análisis, ni de la democracia, si no se consideran las disparidades de las que procede y ayuda a producir.
\end{abstract}

PALABRAS CLAVE: Estado, capital, disparidades, clase, relaciones patrón-cliente

State, Capitalism and Rural Communities. Production Process of Social Inequality In Campeche, Mexico

In this paper I explore the processes of formation of certain social groups, the State and the capital in a rural zone of South Campeche, Mexico. I argue that the State has not been the prime producer of the social life of the subjects, but part of its production processes. In such processes, the forms and categories of the State have been produced unequally by groups and classes to fix the asymmetries between them. In Campeche, the State has been the institutional result of the production of categories such as natives and settlers, Maya and mestizos, boss and client, as hierarchy. Therefore, the State should not be focused as the starting point of the analysis, nor democracy, without considering the inequalities from which it proceeds and which contributes to produce.

UBALDO DZIB CAN KEYWORDS: State, identities, inequalities, class, boss-client relation 


\section{Introducción}

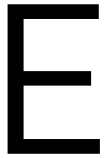

n este trabajo ensayo un cambio de énfasis en las relaciones de producción recíproca entre Estado, capital y grupos sociales, reconocidas por numerosos estudiosos. En lugar de centrarme en la comprensión del Estado y el capital, como ha hecho la literatura que los ha entendido como sitios de producción cultural (Corrigan y Sayer, 2007; Joseph y Nugent, 2002), priorizo el análisis de la formación de los grupos sociales para eliminar el fetiche del Estado. Aunque lo considero un medio poderoso de construcción social, comprendo que él mismo ha sido producto de las acciones y relaciones entre la gente. Esta mirada presenta una faceta subestimada del Estado, no su papel como el dios mortal regulador de la sociedad, sino como parte de procesos más prosaicos de producción de sus propios creadores y de los ordenamientos sociales que éstos han construido.

Estudio los procesos de producción de los grupos sociales, sus desigualdades y sus instituciones, desde mediados del siglo XX hasta la primera década del XXI, en una zona de las antaño selvas del sur de Campeche. En concreto, me centro en los procesos de producción de identidades y disparidades culturales, políticas y de clase social, tanto de los grupos rurales que se formaron en relación con las políticas de intervención del Estado de bienestar y su posterior repliegue neoliberal en el área, como entre éstos y otros translocales con los que se han involucrado en la producción de sus vidas.

Centrada en el pueblo de Chicbul, con 1692 habitantes en 2010, la etnografía explora las acciones cotidianas de la gente, sus luchas y alianzas, sus representaciones y valoraciones, en el marco de espacios entrelazados por jerarquías, primordiales en la construcción de sí mismos —el ejido y la comunidad—, así como en el de la interrelación de éstos con los mercados laborales regionales y las disputas por los gobiernos municipales. Asimismo, vislumbro estos procesos en relación con dinámicas mayores de formación del Estado y el capital en la zona, para las cuales los grupos y espacios locales han sido tanto medios como resultados de sus procesos de formación. 
Exploré esas dinámicas en la producción de relatos de varios grupos sociales sobre la formación del poblado, disputas por el control del ejido y la comunidad, e historias de vida de hombres y mujeres de generaciones y grupos de identidad diversos, con énfasis en la participación política y la trayectoria laboral. Los posicionamientos, representaciones y valoraciones de los grupos, que revelaban la construcción de identidades y desigualdades entre sí mismos y respecto a otros, emergían en las versiones sobre los procesos estudiados. También rastreé las huellas de actores y procesos mayores en la historiografía regional, la hemerografía y la investigación documental.

En las dos primeras secciones ilustro mi enfoque con la exposición de la producción recíproca del Estado interventor y el pueblo y ejido de Chicbul, y sus grupos sociales en el periodo de 1950 a 1982. En los apartados restantes analizo los cambios en los grupos sociales y su producción de instituciones locales de gobierno como medios para redefinir sus jerarquías durante la construcción del Estado neoliberal y la profundización de relaciones capitalistas, de 1982 a 2010.

\section{Desigualdades sociales y Estado}

Mi propósito en este trabajo es explorar los procesos de producción de desigualdades entre grupos y clases sociales, la influencia de esas disparidades en la construcción de las instituciones de Estado, y el papel de estas instancias en la producción de las asimetrías. Poner en primer lugar la formación de los grupos y sus jerarquías en los estudios del Estado constituye una estrategia metodológica que suscribe la sugerencia de varios autores, en particular Abrams (1988) y Foucault (1988: 16-17), de centrarnos en el análisis de las relaciones de poder y dominación social más que en las instituciones. Asimismo, comparte la mirada antropológica que da prioridad a la comprensión de las prácticas y relaciones entre los sujetos sociales que pueden cristalizarse en los procesos de formación del Estado (Paley, 2002: 469-470).

Aunque Corrigan y Sayer (2007: 42-47) reconocen las relaciones de producción recíproca entre Estado y sociedad, por razones de espacio se centraron en analizar los aspectos culturales de formación del primero: el efecto de las rutinas, rituales y actividades de sus instituciones en la creación de las identidades sociales a lo largo de ocho siglos en Inglaterra. En este sentido, el Estado puede ser visto como una revolución cultural. Tanto la identidad totalizante, que constituye la "comunidad nacional imaginada", como las individualizantes, que nos categorizan como ciudadanos, electores, contribuyentes, etc., definen modos de pensamiento y acción social legítimos que hacen obvia la vida que vivimos. Aunque suscribo esto, también me interesa explorar los procesos recíprocos, es decir, cómo esas categorías y rutinas gubernamentales pueden ser apropiadas y redefinidas por los grupos sociales, que las usan para reproducir las desigualdades de género, etnia y clase, que han generado en sus procesos de formación social. En este sentido, señalo que el Estado mismo es resultado de procesos sociales de construcción en los que han participado de manera desigual hombres y mujeres, jóvenes y adultos, colectividades étnicas, grupos del campo y la ciudad y clases sociales en sus procesos de formación.

Cuando enfocamos estos procesos relacionales de formación social, comprendemos que las desigualdades entre los grupos son el resultado de la articulación jerárquica en relaciones de poder ${ }^{1}$ de grupalidades fracturadas por identidades y diferencias

1

Relaciones de poder en el sentido de Foucault (1988: 237240; 2002: 112-117), de estrategias y tácticas entre grupos vinculados y opuestos por identidades y diferencias entre sí, en las que unos tratan de coaccionar y producir las acciones y representaciones de los otros. 
entre sí y respecto a otros (Comaroff y Comaroff, 1992: 51). Establezco las primeras precisiones conceptuales: mientras las identidades y diferencias han constituido formas relacionales de adscripción y autoadscripción entre los grupos a partir de la diversidad cultural y natural humana, como el color de la piel, los genitales, la indumentaria, la lengua, etc., las desigualdades sociales se refieren a la construcción de jerarquías entre las colectividades a partir de esas identidades y diferencias. Sugiero que en los procesos por el control de las condiciones materiales y sociales de su propia producción, con base en dinámicas de inclusión y exclusión relacionadas con sus identidades y diferencias, los grupos han tratado de crear y "congelar" disparidades entre sí al inscribirlas en normas escritas o consuetudinarias; dispositivos que los grupos formalizan, como las membresías que incluyen a unos y excluyen a otros, la creación de cargos jerarquizados, de funciones diferenciadas pero coordinadas, de procedimientos, canales e instancias para la toma legítima de decisiones, etc. (Callon y Latour, 1981: 283-286; Foucault, 2004: 204-206; Comaroff y Comaroff, 1992: 28-30). La organización compleja de estas formas sociales puede llamarse institución de gobierno. Con esta categoría no me refiero sólo a las estructuras burocráticas del Estado, retomo la sugerencia de Foucault (1988: 15) de restaurar en el término "gobierno" su sentido amplio del siglo XVI, de dirección de las conductas de los sujetos en los dominios más diversos de la vida social: gobierno de un hogar, escuela, cárcel, fábrica, etc. Es decir, el término designa los aparatos y dispositivos que estructuran el tiempo y los espacios en los que transcurre la vida de las personas (Foucault, 2004: 199-230), por lo tanto, modelan un orden social que produce las prácticas y representaciones de los grupos. Así, las instituciones de gobierno son a la vez producto de relaciones de poder y estructuración de desigualdades, y medios para producirlas o redefinirlas.
Estos procesos se comprenden mejor con un ejemplo procedente de los bosques tropicales del municipio de Carmen, la constitución de uno de los primeros poblados y ejidos de la región de Sabancuy, en el marco de la explotación forestal y los procesos de colonización del área, a principios de la década de 1950. Una cuadrilla de taladores de madera asalariados, originarios de varias entidades del sureste de México, estableció la aldea Chicbul en ese periodo. Diez años después arribó al lugar un grupo de solicitantes de tierras del norte del país traído por el gobierno federal con el programa de colonización agraria para fundar un ejido.

Desde su encuentro en Chicbul, los dos grupos construyeron sus identidades internas y sus diferencias al contrastar sus experiencias de vida, trabajo y sus orígenes territoriales. Resumieron esos contrastes en categorías identitarias: los asalariados madereros llamaron a los norteños solicitantes de tierras “colonos", por el programa que los había llevado, y éstos nombraron a los primeros "nativos", por encontrarlos en el lugar y la creencia de que eran originarios de la zona. A partir de esas identidades y alteridades entablaron relaciones de poder en la disputa por el control del poblado y el ejido en formación. Con el apoyo económico y administrativo del gobierno federal, los colonos se apropiaron del ejido y por medio de sus órganos de gobierno, reglas y espacios de toma de decisión empezaron a regular el acceso a la tierra, a los recursos naturales de la selva y a fondos gubernamentales para la agricultura. Así, los colonos institucionalizaron su predominio social sobre los nativos. Es decir, se apoyaron en los procedimientos y regulaciones del ejido para fijar y repetir las rutinas y prácticas que hicieran perdurar las relaciones de dominación.

La categoría institucional de ejidatarios subordinó las identidades y diferencias culturales entre colonos y nativos. Con estas etiquetas, los grupos construyeron la categoría de ejidatarios y 


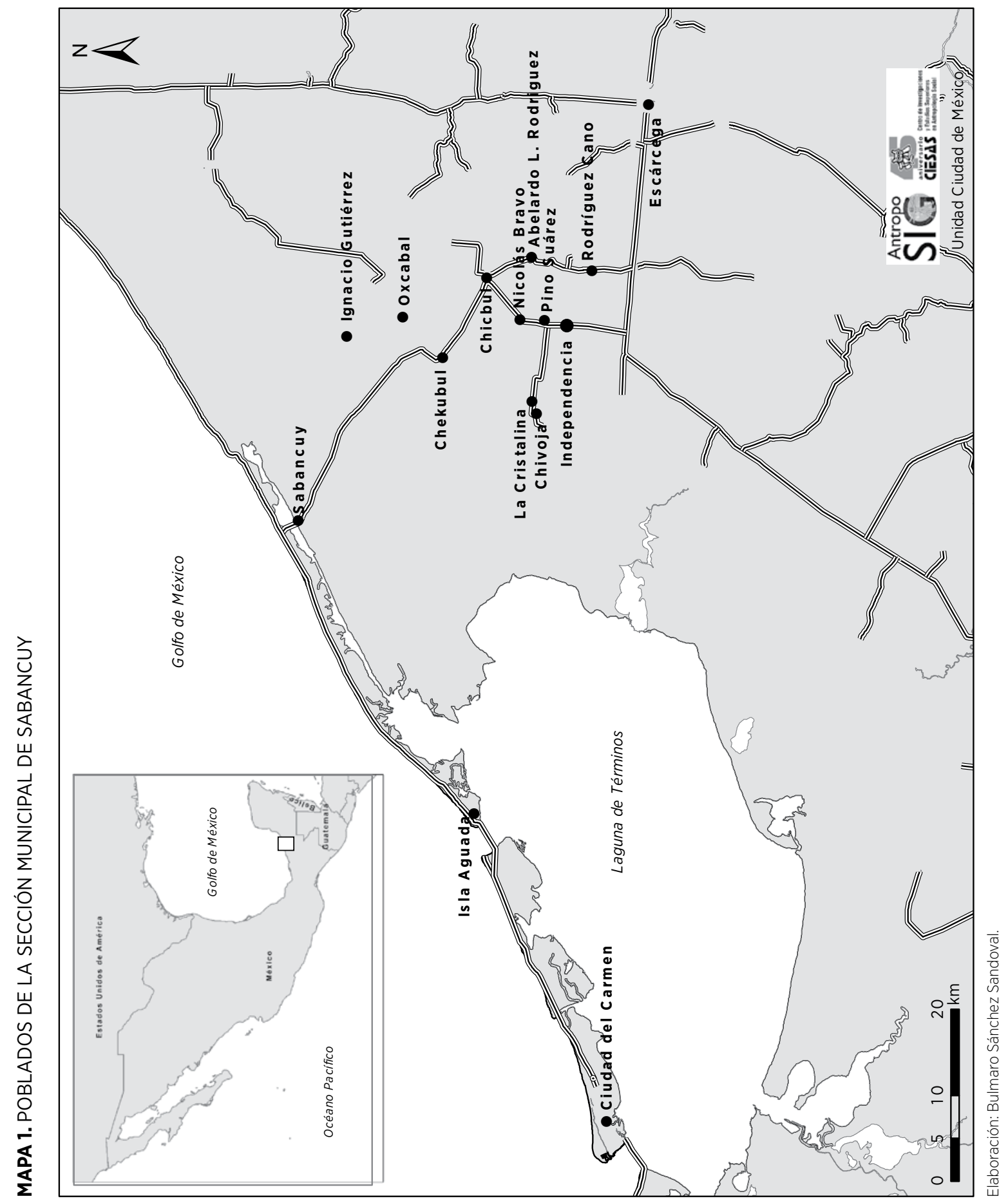


ejecutaron las nociones del ejido como institución de gobierno de manera desigual. Es decir, usaron los órganos de gobierno del ejido, sus normas y procedimientos para incluir a unos y excluir a otros. No era lo mismo ser ejidatario colono, que ejidatario nativo:

Un señor que acaba de morir, se llamaba Emilio Mendoza [líder de los colonos], abogaba siempre por los de ellos, y de pasada también nos daba la mano. Pero siempre la abogación pa' los de ellos, porque los colones pa' los de ellos, nosotros ajuera. Porque inclusive para el asunto de eso de los créditos [agrícolas] primero a los de ellos; si sobraba cupo, pa' nosotros, si al caso sobraba, pero si no sobraba, defiéndete como puedas (entrevista con Adelfo Paul, nacido en 1932, ejidatario de los primeros pobladores madereros, Chicbul, 12 de marzo de 2003). ${ }^{2}$

Colonos y nativos redefinieron y usaron de manera asimétrica los órganos de gobierno y las regulaciones del ejido para perfilar un orden social estratificado que produjera sin cesar las distancias entre ejidatarios colonos dominantes y ejidatarios nativos subordinados. Las instituciones nacieron en el proceso de formación de los grupos, que las emplearon para crear jerarquías entre sí. El uso partidario de sus procedimientos era resultado de sus conflictos y diferencias.

Cuando la composición social de la localidad se transformó por la llegada de nuevos inmigrantes, los colonos influyeron más que otros grupos, por medio del ejido, para excluir a la nueva población de la membresía ejidal y los fondos gubernamentales. Así, contribuyeron a producir y traslapar nuevas asimetrías entre ejidatarios y residentes no ejidatarios o "pobladores".

Al igual que la fractura interna de los ejidatarios, la categoría subalterna de pobladores incluía inmigrantes con identidades y diferencias étnicas entre sí: campesinos mestizos e indígenas mayas. A partir de los enfrentamientos de 1969 entre ejidatarios y pobladores por el ingreso al ejido de los solicitantes mayas y mestizos, se negociarían las nuevas jerarquías entre todos los grupos de identidad y étnicos involucrados (Dzib, 2014b). Con el triunfo de la alianza política de solicitantes mayas y mestizos, bajo la dirección de los primeros, ${ }^{3}$ las categorías de ejidatarios y pobladores serían también desiguales en términos étnicos, con las siguientes particularidades. Las prácticas y discursos políticos producidos por la dirigencia maya en su lucha por el ingreso de campesinos indígenas y mestizos al ejido no enfatizaban reivindicaciones étnicas, sino la construcción de una comunidad sin distinciones de ese tipo. Por ello, en los hechos, por un lado, siempre ha dejado sus fronteras étnicas abiertas a las alianzas políticas y la cooptación de los líderes ejidales colonos y nativos vencidos al grupo político dirigente de la comunidad, y por el otro, se ha esforzado por erosionar los valores y las prácticas sociales de exclusión étnica que inhiben las relaciones de amistad y parentesco ritual — bodas y bautizos - y consanguíneo entre mestizos e indígenas.

En este punto es interesante reproducir la versión de un dirigente maya, dos veces presidente del Comisariado ejidal, sobre cómo se borraron sus diferencias étnicas y políticas con los colonos mestizos y se integró un grupo político con todos los grupos étnicos y de identidad:

2 Los nombres de todos los informantes son seudónimos para mantenerlos en el anonimato.

$3 \quad$ Las condiciones de la lucha que favorecieron la construcción de la dirigencia y el predominio político maya se explican en Dzib (2014b). 
Cuando nos dieron la primera ampliación [1970] ingresamos 57 campechanos. ${ }^{4}$ Pero como esa ampliación no se parceló en un principio, sino que era de uso común, los siguientes campechanos que siguieron llegando - aunque no eran ejidatarioslos dejábamos trabajar la tierra. Cuando los colonos vieron ese gesto de los campechanos de la primera ampliación, comprendieron que no éramos gente mala. Reconocieron que ellos se habían equivocado porque creyeron que la lengua que hablábamos, y no comprendían, la usábamos para hablar mal de ellos. A partir de ahí empezaron a cambiar, poco a poco se fueron borrando las divisiones. Cuando yo fui comisario ejidal [a finales de la década de 1980], fue a propuesta tanto de colonos como de campechanos, de ese grupo de políticos del ejido que se reunían para intercambiar opiniones sobre quiénes podían ser parte del comité ejidal (entrevista con Gaudencio Camaal, nacido en 1939, Chicbul, 13 de junio de 2005).

Los resultados han sido: 1) el predominio político maya y la pérdida de relevancia de los referentes que promovían la construcción de las identidades de colonos y nativos - el programa de colonización para los primeros y la tala de maderas que cohesionaba a los segundos - disolvieron esas categorías y colectividades sociales; 2) las diferencias étnicas han dejado de ser usadas para la construcción de grupos políticos, pero siguen siendo criterios para el mantenimiento del predominio político indígena en las alianzas y directivas ejidales, al menos hasta la primera década del siglo XXI, y 3) en el conjunto del poblado coexisten dos representaciones étnicas: los indígenas mayas, y en menor medida, la población mestiza, en el sentido de "estar revueltos", y los mestizos, que mantienen la distinción en el terreno de la vida cotidiana mediante la mofa por el acento maya traslapado en el habla del español o el uso de categorías peyorativas, como "mayitas" o "mestizada", para referirse a la población indígena.
De cualquier modo, asistimos a la apropiación y producción del ejido en términos étnicos. El ejido, como institución de gobierno local predominante, de 1950 a 1997, ha sido recreado de manera desigual en Chicbul para intentar construir, en lo que parece una contradicción, una comunidad sin fracturas étnicas, pero bajo la dirección política maya.

Desde esta perspectiva, las categorías e identidades sociales propuestas por el Estado - ejidatarios, pobladores; sugerimos también ciudadanos, contribuyentes, etc. - fueron apropiadas, redefinidas y resignificadas por las identidades y diferencias que las colectividades construyeron en sus relaciones y procesos de producción como grupos de identidad (Lomnitz, 1995: 39) y étnicos, pero también las de género, raza y clase social. Aunque las formas y discursos generalizantes del Estado han tratado de ocultar estas asimetrías, los grupos y clases las reproducen en sus apropiaciones culturales particulares. En este sentido, hablamos de la producción de las instituciones de gobierno en los procesos de formación de los grupos y sus diferencias.

\section{Estado, capital y grupos locales}

Esas dinámicas locales también constituían las expresiones históricas particulares de procesos nacionales similares de formación recíproca de grupos sociales jerarquizados y el Estado. Apoyado en el régimen presidencialista definido en la Constitución

4 Cabe señalar que los indígenas mayas que llegaron a Chicbul no se reconocían a sí mismos como indígenas, se autoidentificaban con dos categorías: "mayeros", para distinguirse entre sí en relación con otros, y "campechanos", más genérica, para tratar con técnicos y funcionarios gubernamentales, así como para diferenciarse de la población mestiza procedente de otras entidades del país. En este relato, cuando el informante habla de campechanos se refiere a indígenas mayas. 
de 1917, el llamado Grupo Sonorense, facción revolucionaria triunfante, impulsó desde la década de 1920 el fortalecimiento del ejecutivo mediante la centralización económica, política, militar y fiscal, y la subordinación de los otros niveles de gobierno y poderes de la Unión a esos ámbitos (Zendejas, 2003: 249-251). La nueva clase política posrevolucionaria no sólo disciplinó a los caudillos nacionales opositores y a los jefes militares regionales, sino que contribuyó a formarse a sí misma y a los anteriores empresarios porfiristas como la nueva clase económica preeminente del régimen (Hamilton, 1998: 87-92), al mismo tiempo que empezó a integrar de manera política, económica e ideológica las regiones en una comunidad homogénea nacional imaginada.

La reforma agraria expresaba esta centralización política que, en manos de la burocracia posrevolucionaria, devino en un medio que no sólo contribuyó a construir desigualdades en las localidades, sino entre éstas y la nueva burocracia federal dominante. Los gobiernos de entidades y municipios fueron limitados en términos económicos y fiscales por el ejecutivo federal, y excluidos de la administración del reparto agrario. En esas condiciones, amplias poblaciones rurales y espacios territoriales de sus jurisdicciones fueron sustraídos a su control (Zendejas, 2003: 250-251; Baintenmann, 2007: 81-86). La intervención de las burocracias federales en las localidades, la concentración de los fondos para la agricultura entre los nuevos ejidatarios y la exclusión de otras poblaciones rurales crearon condiciones para que los ejidos se convirtieran en medios institucionales de producción de disparidades locales.

Sin embargo, la centralización política en el ejecutivo y la integración del campo al espacio nacional fueron más allá de la formación de ejidos. En este marco, el ejecutivo contribuyó a producir la vida económica de los nuevos ejidatarios y las poblaciones rurales de la zona desde mediados del siglo XX con varias políticas: la limitación de la explotación forestal privada meramente extractiva heredada del porfiriato; el fomento con créditos, maquinaria y transporte de la producción agropecuaria ejidal orientada al mercado, y el establecimiento de un mercado nacional regulado de productos agropecuarios que incluía la fijación de precios de garantía y la adquisición gubernamental de la producción ejidal. Esas medidas revelaban la relación estrecha entre el Estado y el capital, así como el nuevo modelo nacional en el que ésta se insertaba: se transitaba del Estado liberal porfirista, con escasa injerencia en la economía, a un Estado benefactor, con una amplia regulación sobre ella. En las selvas de la entidad, esos cambios se expresaron en la sustitución de la economía forestal de extracción con inversiones privadas por una producción ejidal financiada por un Estado capitalista.

La producción entrelazada de Estado y capital tuvo su efecto en la redefinición de grupos y clases sociales (Corrigan y Sayer, 2007: 41-47). En los bosques tropicales decayeron las relaciones de disparidad de clase entre los asalariados madereros y los permisionarios privados que los empleaban, ${ }^{5}$ y emergieron relaciones económicas y políticas de control y regulación — también de clase- de las burocracias paternalistas sobre las comunidades ejidales en particular, y las poblaciones rurales en general. A diferencia de los grupos de identidad, que trazaban de manera relacional sus alteridades a partir de símbolos y fronteras culturales construidas por experiencias y valores desiguales compartidos (Lomnitz, 1995: 39), las clases sociales eran resultado de la articulación asimétrica de sus formas de producir, vivir y representarse el mundo, contrastantes pero complementarias. Las relaciones dispares eran condicionadas por el control de la burocracia federal intervencionista sobre los procesos de producción y circulación de recursos económicos, políticos, ideológicos

Empresarios con permiso federal para explotar determinada área de monte tropical. 


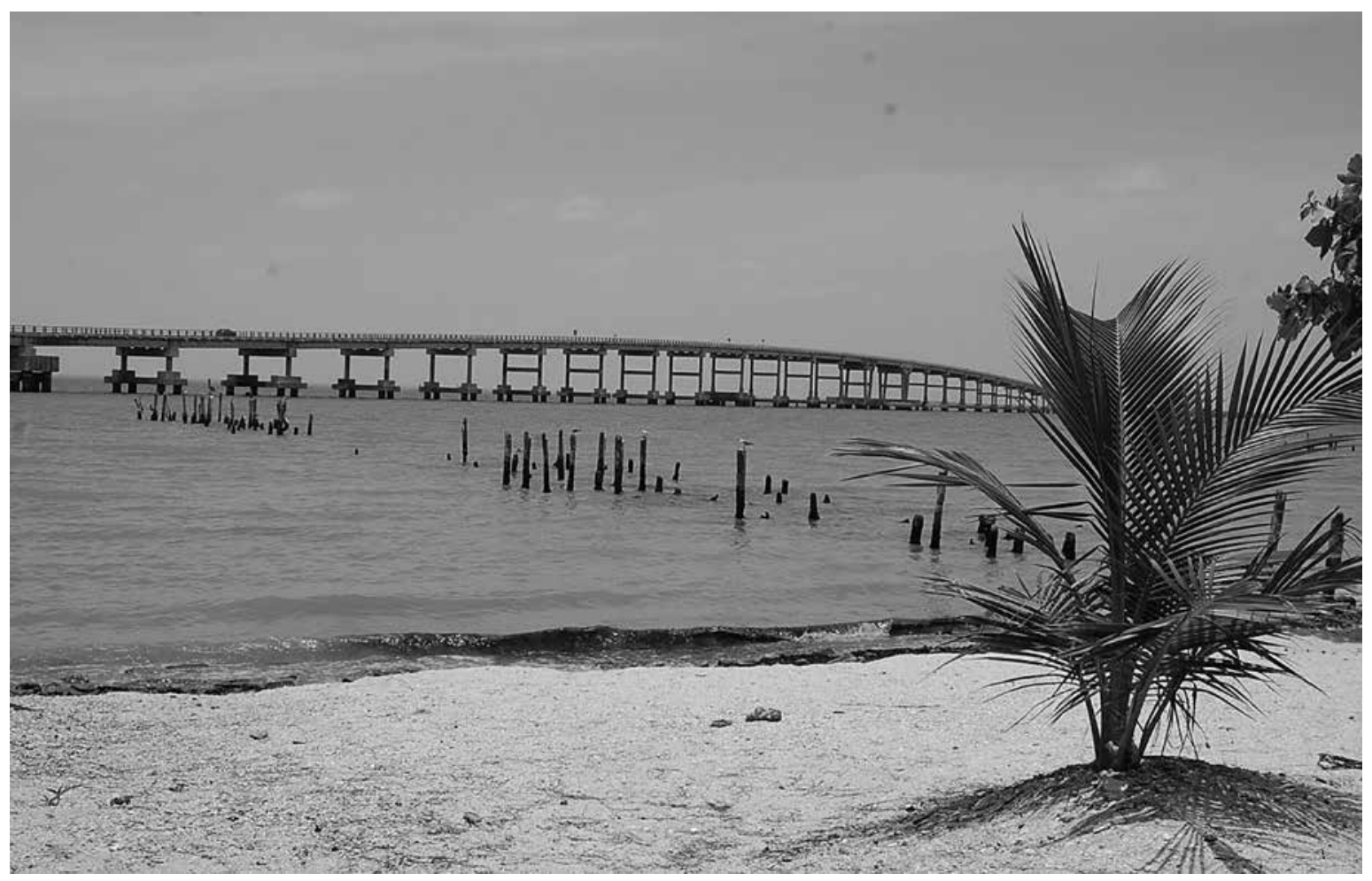

Comisión MeXICANa de FiLmaciones • Puente Zacatal, Ciudad del Carmen, Campeche, julio de 2009.

y materiales, vitales para la reproducción de las colectividades rurales, no sólo en la dimensión económica, sino en el conjunto de la vida social (Bourdieu, citado en Gledhill, 2000: 223).

Así, las instituciones de Estado, producto de relaciones de poder y desigualdades sociales, han sido usadas de manera desigual por los grupos y clases para producir o redefinir las relaciones de disparidad entre ellos. Las instituciones de gobierno, incluyendo al Estado, no han sido entidades neutras que representen la voluntad o el interés general, sino resultado y medio para producir las jerarquías entre los grupos sociales.

A partir de esta comprensión de las instituciones de Estado, aunque insistimos en el análisis de las relaciones sociales, no podemos prescindir de los "aparatos" que han sido medios en la producción de los sujetos y sus jerarquías sociales, como propone
Trouillot (2003) al pretender escapar de la reificación social, como tantos otros analistas. Trouillot considera que, aunque unido a un número de aparatos, el Estado no es un aparato sino un conjunto de procesos y relaciones de poder con efectos sobre la formación de sujetos sociales (2003: 83-84). Lo que subestima es que estas relaciones y prácticas han sido sumamente inestables y evanescentes - como mostraron Callon y Latour (1981: 283-286)—, si no se convierten en rutinas mediante mecanismos organizativos, reglas escritas o consuetudinarias, objetos distribuidos en el espacio para fijar posiciones y relaciones entre personas, e ideologías para intentar legitimarlas y hacerlas duraderas. Lo "social" no sólo son relaciones y prácticas, esa definición debe incluir objetos materiales y procedimientos técnicos producidos y dotados de significados por los seres humanos (Callon y Latour, 1981: 292, 294, 298). 
Los objetos y cosas no sólo son producidos en medio de relaciones sociales y adquieren sentido en ese entramado, incluso pueden ayudar a perpetuarlas. Todos estos constructos constituyen la materialidad de las instituciones y estabilizan y hacen perdurables las relaciones sociales de las que son expresión y fuente. A esto se refería Foucault cuando señalaba que los objetos y dispositivos de una máquina institucional sostienen y producen las relaciones sociales que los creó (2004: 204).

En estos términos, en efecto, las instituciones de Estado pueden entenderse como espacios de relaciones y procesos promovidos de manera desigual por grupos variados, que también han producido objetos, reglas y dispositivos técnicos como partes intrínsecas de las instituciones, para intentar hacer rutinarias las relaciones creadas entre ellos. Como espacios de relaciones entre grupos posicionados de manera asimétrica, también hay luchas y formas desiguales de crear y apropiarse de dispositivos, leyes y políticas, con las que las instituciones se producen en formas histórica y culturalmente específicas, en lugares y momentos diversos. El Estado, entonces, ha sido el resultado institucional de todas esas luchas, invenciones y acomodamientos entre hombres y mujeres de una gama de edades, grupos étnicos y clases sociales en sus procesos de formación. También ha sido un medio para fijar y producir las relaciones asimétricas entre esos grupos y clases, para intentar ocultar esas relaciones de desigualdad bajo su materialidad institucional neutra en el discurso (Abrams, 1988: 78-79), bajo las formas liberales de organización de su aparato, sus leyes y sus discursos. Así, los seres humanos han creado sus instituciones. Éstas no han tenido vida propia ni pueden pensarse al margen de las relaciones de disparidad de las que proceden. No pueden ser concebidas como punto de partida de la revolución o la democracia. Las asimetrías sociales han sido inherentes a las instituciones en el sentido de ser tanto su producto como su medio.

\section{Estado neoliberal y redefiniciones de las jerarquías locales}

El Estado de bienestar y la economía regulada, como condiciones generales de producción de los grupos de Chicbul, incluso sus relaciones jerárquicas con las burocracias federales, empezaron a reformularse en la década de 1990 como consecuencia de procesos que habían comenzado diez años atrás. El colapso financiero del Estado de bienestar, en 1982, preparó el terreno para el ascenso de los tecnócratas, nueva facción dominante en la clase política. Este grupo impulsó un proyecto político-económico orientado a reducir las atribuciones económicas del Estado interventor, que significaría una ampliación de las relaciones capitalistas y la profundización de las desigualdades sociales.

Las principales vertientes entrelazadas de esas transformaciones serían, por un lado, la sustitución del modelo de proteccionismo económico e intervención estatal en la economía por uno de apertura a la participación de la iniciativa privada nacional e internacional; por el otro, la descentralización administrativa y fiscal entre órdenes de gobierno impulsada por reformas sucesivas al artículo 115 constitucional y otros instrumentos de política pública, ${ }^{6}$ que extendieron las capacidades

Las reformas al artículo 115 constitucional de 1983 y 1999 han promovido las atribuciones de los ayuntamientos en la gestión del desarrollo regional y la provisión de bienes y servicios públicos a las localidades bajo su jurisdicción. El diseño, en 1997, del Programa para un Nuevo Federalismo integró 27 de 32 programas federales a mediano plazo que contemplaban la redistribución de responsabilidades y recursos a estados y municipios. Las modificaciones sucesivas al Sistema Nacional de Coordinación Fiscal transfirieron potestades tributarias a las administraciones estatales y municipales, y las reformas a la Ley de Coordinación Fiscal han regulado los ramos 26,28 y 33, que establecen fondos presupuestales para entidades y municipios (Arroyo, 2003: 58-63, 67-68). 
financieras, ${ }^{7}$ legislativas, de planeación y gobierno de entidades y municipios (Arroyo, 2003: 56-63). La lenta y conflictiva construcción, desde los setenta, de un sistema pluripartidista de competencia electoral fue desplazando el modelo de partido de Estado y canalizó cuantiosos recursos económicos a la formación de partidos nacionales y sus actividades de proselitismo y competencia por cargos públicos en los tres niveles de gobierno. ${ }^{8}$ No obstante, este último proceso no puede atribuirse por completo al neoliberalismo, sino que se intensificó a partir de 1988 por la emergencia de un grupo político nacionalista escindido del partido oficial - Partido Revolucionario Institucional (PRI)que llevaría su lucha contra el ajuste económico al terreno electoral.

Para empezar, el traslape de estos procesos condicionaría un cambio en las relaciones jerárquicas entre instituciones locales de gobierno. El repliegue del gobierno federal en el campo se tradujo en una disminución de $50 \%$ de las inversiones productivas, de 30000 millones en 1982, a 15000 millones en 2006 (Merino, 2009: 8). Esta reducción del presupuesto público para la agricultura, que de manera usual fluía a las comunidades por medio del ejido, en Chicbul debilitó a esta institución de gobierno como medio para construir desigualdades. Al mismo tiempo, emergieron otras expresiones locales de instituciones que empezaron a ser beneficiarias del presupuesto público: los partidos políticos y la comisaría municipal. Ésta representaba a los residentes de la localidad, también a los ejidatarios, y dependía de los ayuntamientos. No obstante, la disminución de corte neoliberal de los apoyos productivos al campo, por sí sola, no propició esa redefinición de jerarquías, sólo fue una condición usada por las elites político-económicas de la cabecera municipal para construir su intromisión política en las localidades de las que habían estado excluidas por la limitación presupuestal de los ayuntamientos impuesta por la burocracia centralizadora del Estado de bienestar anterior. ${ }^{9}$
Las elites empezaron a apoyarse en las comisarías municipales para hacer llegar a las localidades los programas, servicios y obras que administraba el ayuntamiento $\mathrm{u}$ otros niveles de gobierno. Con este posicionamiento de las comisarías — que desde entonces han sido la institución preeminente de gobierno en Chicbul-, las elites municipales habilitaron sus vínculos políticos y administrativos de dominación sobre las poblaciones rurales, que incluían tanto a ejidatarios como a pobladores.

En Chicbul, esta redefinición de jerarquías de instituciones estuvo asociada a cambios y continuidades en la formación de los grupos, sus identidades y disparidades sociales. La institución más atractiva, que concitaba las luchas político-electorales más intensas por su control, empezó a ser la comisaría municipal, que además era la vía de acceso a los beneficios sociales que distribuía el Estado, y en menor medida, los partidos políticos. Sin embargo, aunque la reorganización de jerarquías benefició a los "pobladores", no sólo a los ejidatarios, no ha influido, por ahora, en el predominio social de los primeros sobre los segundos. Esto se debe quizá a que

Según Aguilar Camín (2016: 21), entre 2000 y 2015, la federación transfirió a entidades y municipios recursos voluminosos que pasaron de 682000 millones a 1390000 millones de pesos. La reforma de 1996 incrementó de manera sustancial el financiamiento a los partidos: 596 millones de pesos ese año, 2111 millones en 1997, 3000 millones en 2000 y 4171 millones en 2006. La reforma de 2014 aumentó los recursos a los partidos en las contiendas estatales. Para 2015, el costo oficial de los procesos electorales era de 50319 millones de pesos, para hacer de la democracia mexicana la quinta más cara del mundo (Ugalde, citado en Aguilar, 2016: 19).

9 Entre las medidas usadas por la elite del ayuntamiento de Carmen para intervenir, figuran la designación de los comisarios municipales mediante una reforma a la Ley Orgánica de los Municipios del Estado, en 1994 (LV Legislatura del Congreso del Estado de Campeche, 1994) y el impulso a la ampliación de facto de las atribuciones de la comisaría municipal a costa del ejido (Dzib, 2014a: 376-387). 
la comisaría municipal ha estado más limitada como medio para construir disparidades sociales porque los programas y servicios que distribuye se orientan más a la asistencia social y el equipamiento urbano que al fortalecimiento de la capacidad productiva y la economía de los grupos rurales. También porque dentro de los grupos políticos que se disputan su control, los ejidatarios han conservado la mayor iniciativa política, aunque ahora expresen que trabajan por todo el pueblo y no sólo por ellos.

Aunque estos cambios no propiciaron el ascenso de los pobladores sobre los ejidatarios, condicionaron la producción de otro tipo de disparidades: la formación de una base clientelar que busca favores y de un estrato de líderes, hombres y mujeres, que tratan de satisfacerla con recursos que distribuyen las elites municipales para comprometer lealtades.

Si bien el ascenso de los partidos y la comisaría municipal propició la unidad de ejidatarios y pobladores en los grupos políticos en disputa, también favoreció fracturas partidistas. Los grupos políticos de ejidatarios y pobladores, de mayas y mestizos, se fragmentaron, no en relación con la membresía ejidal o las distinciones étnicas, sino entre las colectividades dominantes por tradición identificadas con el PRI, por un lado, y la formación de una oposición política que comenzó vinculada al Partido de la Revolución Democrática (PRD) desde finales de la década de 1980, y terminó a principios del nuevo milenio integrada al Partido Acción Nacional (PAN), por el otro. Con todo, las instituciones locales de gobierno siguen siendo producidas en términos étnicos para mantener el predominio político de los ejidatarios mayas.

\section{Crisis y empobrecimiento de los grupos rurales}

En las nuevas condiciones de formación del Estado neoliberal y las relaciones capitalistas, quizá las jerarquías más trascendentes en Chicbul no sean las construidas por los grupos locales, sino la redefinición de sus relaciones económicas y políticas de desigualdad de clase respecto a grupos translocales. Para entender este proceso debemos conocer los efectos diferenciales que las políticas neoliberales posibilitaron en las condiciones de vida de los grupos, tanto locales como no locales, y las modalidades asimétricas de apropiación de las nuevas instituciones de ambos.

El repliegue del gobierno federal en materia de fomento productivo y regulación del mercado de productos agropecuarios propició en el Sur de la entidad, desde finales de la década de 1980, la debacle de su economía, basada en los cultivos comerciales de arroz y caña de azúcar. La otra vertiente de la política neoliberal para el campo — las reformas al artículo 27 constitucional y el Programa de Certificación de Derechos Ejidales y Titulación de Solares (Procede) - , que buscaba convertir la tierra en una mercancía que atrajera inversión de capitales (Arias, 2008: 368-370), no dio resultados en la zona sino hasta 2010. El cultivo de chile verde de la década de 1990, financiado con capitales comerciales foráneos, había colapsado, víctima de las fuerzas del mercado que depreciaron su valor hasta hacerlo no rentable para los productores. La producción de palma africana, financiada con recursos gubernamentales, privados y sociales, había provocado más conflictos que sinergias entre los empresarios de la extractora y los ejidatarios productores por el precio del producto, lo que causó el cierre de la planta en 2003, a tres años de su inauguración (Tribuna de Campeche, 2006).

El complemento del repliegue económico del Estado fueron las políticas de gasto social. Por un lado, el gobierno federal desapareció instituciones vinculadas al apoyo financiero y los subsidios productivos al campo, y por el otro, instituyó programas asistenciales de combate a la pobreza extrema, como Solidaridad, Oportunidades y Educación, Salud y Alimentación (Progresa), orientados a respaldar las 


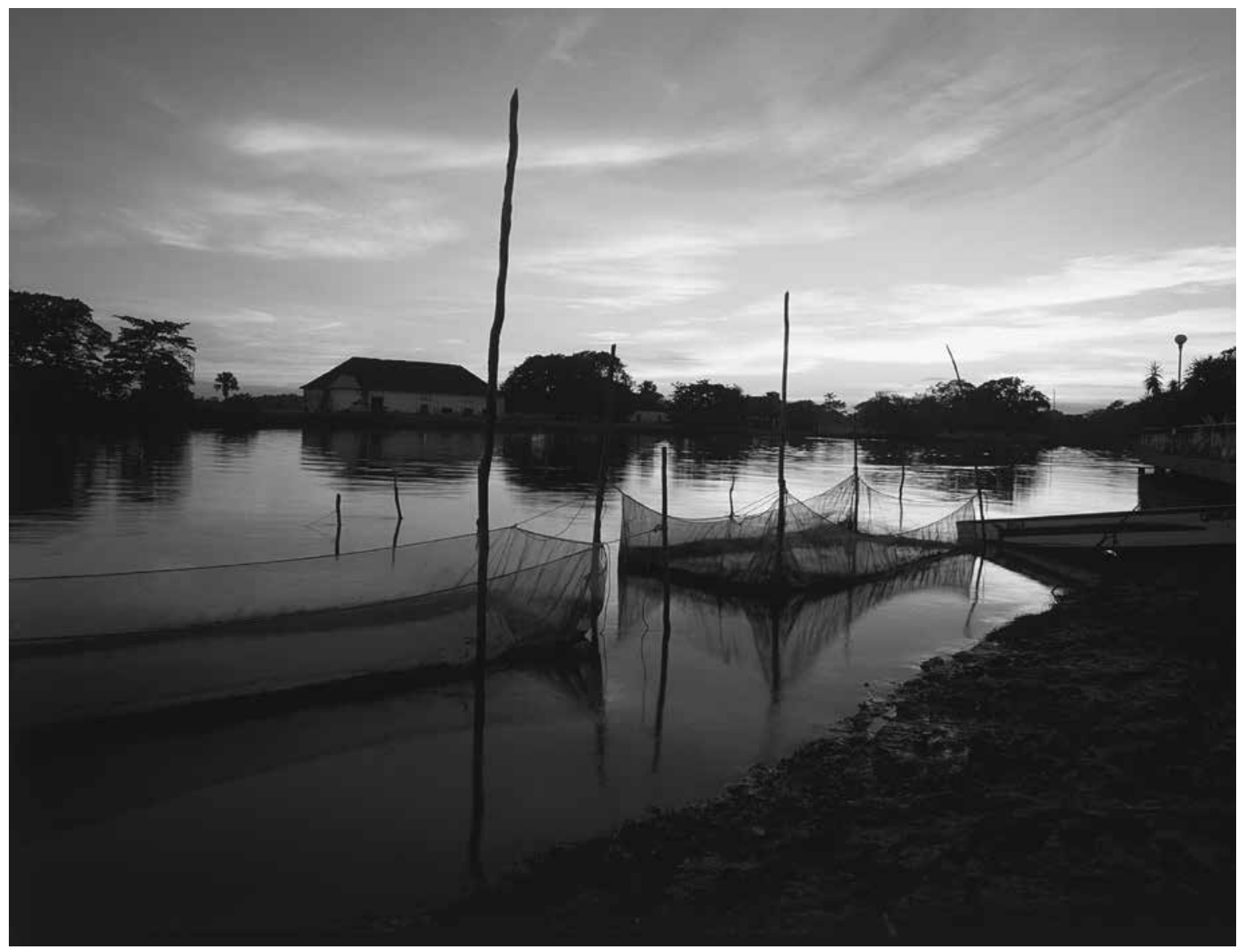

Comisión MeXICANA de FILmaCiones • Sabancuy, Campeche, septiembre de 2018.

necesidades de consumo de las poblaciones más necesitadas. Así, la propuesta del gobierno neoliberal para el campo puso más énfasis en paliar la disminución del ingreso y el consumo de los mexicanos más pobres que en potenciar su capacidad productiva, de generación de riquezas y autosuficiencia económica (Herrera, 2004: 131-134). Lo irónico de estas políticas era que navegaban a contracorriente de lo que establecía el discurso oficial, pues parecían más orientadas a fomentar la perenne dependencia de los grupos rurales empobrecidos respecto a dádivas para mejorar su consumo, que a cimentar el desarrollo de sus fuerzas productivas como base para su transformación en ciudadanos independientes del Estado.
En consecuencia, las pretensiones gubernamentales de reactivación del campo por la vía neoliberal fracasaron con estrépito en la entidad. Por un lado, el gobierno impulsó un gasto social con visión asistencialista y menos responsabilidades económicas y recursos públicos para inversiones productivas (Merino, 2009: 8); por el otro, con sus políticas jurídicas y económicas de apoyo a los empresarios, no ha conseguido que la iniciativa privada capitalice el campo.

En los poblados rurales de Sabancuy, después del fracaso de los proyectos neoliberales de finales de la década de 1990, los grupos sociales empezaron a enfrentar una severa crisis económica. Según el 
Censo General de Población y Vivienda de 2000, 90\% de la población ocupada que residía en esta zona sobrevivía con ingresos que no superaban los dos salarios mínimos (INEGI, 2000). ${ }^{10}$ En esas condiciones de crisis de la agricultura, reducción de subsidios y apoyos para la producción, y resultados limitados de los proyectos agrícolas neoliberales, la mayoría de la población de Chicbul se vio obligada a diversificar su economía y buscar opciones complementarias de ingresos, dentro y fuera de sus poblados. Muchos jóvenes de ambos sexos emigraron a Ciudad del Carmen para intentar emplearse en plataformas de Petróleos Mexicanos (Pemex) o en las empresas del sector servicios y comercio de la isla, que se multiplicaron por influjo del auge petrolero; un número cada vez mayor de mujeres se autoempleaban en la cría de animales de patio, venta de antojitos o productos por catálogo para el hogar y el arreglo personal, y muchos hombres y también mujeres se sumaron a la experiencia de la migración a Estados Unidos. ${ }^{11}$

\section{La constitución de la elite político-empresarial carmelita}

Mientras los grupos de las comunidades rurales se empobrecían y el gobierno federal no lograba atraer y consolidar la inversión de capitales locales o foráneos en las actividades agropecuarias, sus políticas económicas incentivaban la participación de la iniciativa privada campechana y extranjera en algunos rubros de la industria petrolera en Ciudad del Carmen. Esas políticas fueron aprovechadas por la elite económica y política tradicional que controlaba, desde mediados del siglo $\mathrm{Xx}$, tanto el ayuntamiento como la economía, por medio de la pujante industria del camarón, surgida en esos años. La apertura de Pemex a la inversión de capital nacional y transnacional, desde el sexenio de Carlos Salinas (1988-1994), promovió la formación de compañías empresariales carmelitas o bien su asociación con grupos transnacionales que firmaban contratos con la paraestatal para proporcionarle servicios y tecnología (Vadillo, 2000: 75-76). Asimismo, los empresarios de la elite carmelita multiplicaron sus pequeños negocios comerciales y de servicios incentivados por el auge petrolero en la isla. El impulso a las inversiones de particulares en la cabecera municipal ampliaría el mercado de trabajo asalariado para la población rural expulsada por la crisis del campo, por lo tanto, favorecería la construcción de vínculos desiguales de clase entre las elites municipales y los grupos rurales.

Las disparidades económicas, no obstante, no serían las únicas jerarquías sociales que las nuevas políticas posibilitarían entre los empresarios municipales y los grupos rurales. La descentralización administrativa entre niveles de gobierno y las políticas electorales fortalecieron en economía y política la presencia de los gobiernos municipales y partidos en el territorio nacional. El atractivo combinado de ambas instituciones para las elites político-económicas regionales intensificó sus disputas electorales por los ayuntamientos (Dzib, 2014a: 376).

En el municipio de Carmen, desde mediados de la década de 1990, con los recursos económicos, políticos y jurisdiccionales que les posibilitó el ayuntamiento, las elites político-empresariales intervinieron en edificación de obras, dotación de servicios y gestión en general del desarrollo municipal en los poblados rurales de los cuales estuvieron excluidas por el gobierno federal. Esta intromisión

10 En 2000, para el área geográfica C, a la que pertenecía Campeche, el salario mínimo era de 32.70 pesos. Es decir, 90\% de la población rural ganaba 65.40 pesos o menos (Conasami, 2016). Este ingreso era insuficiente para adquirir la canasta básica, cuyo costo se estimó ese año en 90.23 pesos (CEFP, 2009).

11 Información procedente de observaciones in situ y diálogos informales con informantes en las temporadas de campo 2003 y 2008. 
hilvanó las jerarquías administrativas entre las localidades rurales y sus cabeceras de sección y municipio, antes desdibujadas, y fue favorecida por el retraimiento de las inversiones federales en proyectos productivos e infraestructura en las localidades. Es decir, en la etapa neoliberal, las elites políticas y empresariales suplantaron a las burocracias federales del Estado de bienestar en las relaciones de clase con las poblaciones rurales.

La intervención de las elites no sólo era en acatamiento de sus nuevas obligaciones de desarrollo municipal como gobernantes, sino también resultado de su apropiación del ayuntamiento con fines político-electorales. En las luchas por los votos, las facciones han usado las atribuciones administrativas y los recursos económicos de los ayuntamientos y los partidos, no para formar ciudadanos, sino para construir clientelas. Han promovido el apoyo electoral hacia sus gobiernos y candidaturas con el uso partidista de los programas de gobierno y la ejecución de obras tanto en las cabeceras como en los poblados rurales (Dzib, 2014a: 376-390).

\section{Desigualdades clientelares y de clase}

La fragilidad económica de la mayoría de la población de Chicbul, tanto de ejidatarios como de no ejidatarios, condicionó las formas limitadas en que se apropiaron de las instituciones emergentes y entablaron relaciones de disparidad con grupos translocales. La subordinación de clase de algunos grupos rurales por la inserción laboral de sus jóvenes de ambos sexos en las empresas de las elites de Ciudad del Carmen era, hasta la primera década del nuevo milenio, una opción entre varias, urgida por las fuentes de ingresos deprimidas de sus grupos domésticos.

Por el mismo apremio económico se han acercado a los partidos y el ayuntamiento, y han entrado a las redes de control político clientelar. La vulneración de sus ingresos económicos acentuó su dependencia hacia las dádivas de las agencias de gobierno y de los partidos políticos con actividad creciente.

En esas condiciones de vulnerabilidad, los grupos sociales han carecido de autonomía para exigir acceso a servicios y obras públicos, y programas de combate a la pobreza como parte de sus derechos sociales; por el contrario, lo han mendigado como favor. Se han visto forzados a empeñar sus derechos políticos de sufragio al mejor postor partidista. En otros términos, los grupos de Chicbul han ejercido sus derechos sociales y políticos, no como ciudadanos libres, sino como clientes subalternos que intercambian sus votos y apoyo al gobierno y los partidos por acceso a salud, educación, vivienda, becas, despensas y programas de desarrollo social.

La apropiación de estas instituciones emergentes como clientela también ha sido desigual y ha generado disparidades políticas entre la población, pues ha requerido la formación de un estrato de líderes, hombres y mujeres, que coordinen la formación del clientelismo en sus localidades, dedicado a la búsqueda de lealtades y adhesiones para las elites municipales de los partidos y el ayuntamiento a cambio de la gestión de servicios y apoyos gubernamentales para los grupos rurales. Además de la primacía en los beneficios materiales y económicos que reciben, los líderes también obtienen como remuneración política el ascenso a cargos de representación en sus partidos y gobierno de su localidad.

\section{Conclusiones}

En Chicbul, el Estado y sus relaciones con el capital se han constituido de manera desigual como parte de los procesos de producción de sus grupos sociales y sus jerarquías respecto a grupos no locales. Sus políticas, dispositivos y categorías han sido construidos con diferencias entre colonos y nativos, mayas y mestizos, poblaciones rurales y elites municipales, 
campesinos y burocracias gubernamentales. Los seres humanos han creado sus instituciones. Éstas no han tenido vida propia ni pueden ser pensadas al margen de las relaciones de disparidad de las que proceden. Por lo tanto, el Estado no debe concebirse como punto de partida del análisis ni de la revolución o la democracia. Hacerlo así es oscurecer nuestra comprensión de las lógicas profundas de los procesos de construcción de las jerarquías.

Aislar la construcción del sistema pluripartidista de competencia electoral llevó a muchos pensadores, desde principios de la década de 1990, a hablar de la transición a la democracia y la construcción de ciudadanías, pero desde mi enfoque ese cambio fue impulsado por un embate neoliberal de construcción de relaciones capitalistas entre grupos nacionales y locales. En Chicbul, esta producción conjunta de Estado y capital fue la expresión institucional de la redefinición de las subordinaciones de clase de los grupos rurales: de sus relaciones con la burocracia interventora a sus vínculos con las elites político-empresariales del municipio. Sin embargo, estas nuevas conexiones de clase han sido oscurecidas por el predominio de instituciones políticas, como partidos y gobiernos municipales, asociadas a la democracia electoral. Estas relaciones han aparecido como vínculos entre autoridades y ciudadanos, pero las formas en que los grupos se han apropiado y redefinido las instituciones que aseguran tales nexos no han sido democráticas, sino que han estado sujetas a sus jerarquías de clase, es decir, como poblaciones rurales empobrecidas y elites políticoempresariales dominantes. El intercambio desigual de lealtades por favores políticos ha constituido una de las formas de organización de la participación política asimétrica de estos grupos sociales. En este caso, los partidos y los gobiernos municipales sólo han sido medios institucionales para producir las disparidades de clase como asimetrías políticas entre patrón y cliente. $\mathrm{D}$

\section{Bibliografía}

Abrams, Philip, 1988, "Notes on the Difficulty of Studying the State (1977)", en Journal of Historical Sociology, vol. 1, núm. 1, pp. 58 -89.

Aguilar Camín, Héctor, 2016, “Nocturno de la democracia mexicana”, en Nexos, vol. 38, núm. 461, pp. 17-26.

Arias, Patricia, 2008, "De la redistribución a la titulación. Los campesinos en dos modelos de reforma agraria”, en José Luis Sefoó (coord.), Desde los colores del maíz. Una agenda para el campo mexicano, vol. 1, El Colegio de Michoacán, Zamora, pp. 361-380.

Arroyo, Francisco, 2003, “Innovaciones en las reglas del gasto público federal 1995-2000”, en Yolanda Meyenberg y J. Mario Herrera (coords.), Las reglas y los comportamientos: 25 años de reformas institucionales en México, Universidad Nacional Autónoma de México-Instituto de Investigaciones Sociales, México, pp. 55-119.

Baitenmann, Helga, 2007, "Reforma agraria y ciudadanía en el México del siglo xx”, en Francisco J. Gómez Carpinteiro (ed.), Paisajes mexicanos de la reforma agraria, El Colegio de Michoacán/Benemérita Universidad Autónoma de Puebla/Consejo Nacional de Ciencia y Tecnología, México, pp. 71-95.

Callon, Michel y Bruno Latour, 1981, "Unscrewing the Big Leviathan, or How Actors Macro-Estructure Reality and How Sociologist Help Them To Do So", en Karin D. Knorr-Cetina y Aaron Cicourel (eds.), Advances in Social Theory and Methodology. Towards an Integration of Macro and Micro Sociologies, Routledge and Kegan Paul, Londres, pp. 277-303.

Centro de Estudios de las Finanzas Públicas (CEFP), 2009, "Evolución de los precios de la canasta básica y su impacto en los salarios y el empleo". Disponible en línea: <http://www.cefp.gob.mx/intr/edocumentos/pdf/cefp/2009/cefp0422009.pdf>. Consultado el 25 de marzo de 2017.

Comaroff, John y Jean Comaroff, 1992, Ethnography and the Historical Imagination, Westview Press, Boulder.

_, 2004 , "Criminal Justice, Cultural Justice. The Limits of Liberalism and the Pragmatics of Difference in the New South Africa", en American Ethnologist, vol. 31, núm. 2, pp. 188-204. 
Comisión Nacional de los Salarios Mínimos (Conasami), 2016, "Salarios mínimos generales por áreas geográficas 1992-2016". Disponible en línea: <http://www.conasami.gob.mx/pdf/salario_minimo/2016/salarios_area_geo_2016.pdf>. Consultado el 30 de mayo de 2016.

Corrigan, Philip y Derek Sayer, 2007, “El gran arco: la formación del Estado inglés como revolución cultural. Introducción y postdata”, en María L. Lagos y Pamela Calla (comps.), Antropología del Estado. Dominación y prácticas contestatarias en América Latina, Instituto Nacional de Derechos Humanos/Programa de las Naciones Unidas para el Desarrollo, La Paz, pp. 39-116.

Dzib Can, Ubaldo, 2014a, Patriarcado, clase y poder. Procesos de producción de igualdades y disparidades sociales en Sabancuy, Campeche, 1940-2010, Secretaría de Cultura del Gobierno del Estado de Campeche, Campeche.

—_, 2014b, "Etnicidad fracturada. La construcción del predominio político maya sobre la población mestiza rural de Chicbul, Campeche, 1969-fines del siglo xx", en Estudios de Cultura Maya, vol. 43, pp. 127-156.

Foucault, Michel, 1988, "El sujeto y el poder", en Revista Mexicana de Sociología, vol. 50, núm. 3, pp. 3-20.

__ 2002 [1977], Historia de la sexualidad, t. 1: La voluntad de saber, Siglo XXI Editores, México.

—_, 2004 [1976], Vigilar y castigar. Nacimiento de la prisión, Siglo XXI Editores, México.

Gledhill, John, 2000, El poder y sus disfraces. Perspectivas antropológicas de la política, Bellaterra, Barcelona.

Hamilton, Nora, 1998 [1983], México: los límites de la autonomía del Estado, Era, México.

Herrera, J. Mario, 2004, "Instituciones, focalización y combate a la pobreza”, en Yolanda Meyenberg y J. Mario Herrera (coords.), Las reglas y los comportamientos: 25 años de reformas institucionales en México, Universidad Nacional Autónoma de México-Instituto de Investigaciones Sociales, México, pp. 123-173.

Instituto Nacional de Estadística y Geografía (INEGI), 2000, XII Censo general de población y vivienda 2000. Principales resultados por localidad, Sistema Contar 2000, ITER Campeche, Instituto Nacional de Estadística y Geografía, México, disco compacto.

Joseph, Gilbert M. y Daniel Nugent, 2002 [1994], “Cultura popular y formación del Estado en el México revolucionario”, en Gilbert M. Joseph y Daniel Nugent (comps.), Aspectos cotidianos de la formación del Estado. La Revolución y la negociación del mando en el México moderno, Era, México, pp. 31-52.

Lomnitz, Claudio, 1995, Las salidas del laberinto. Cultura e ideología en el espacio nacional mexicano, Joaquín Mortiz-Planeta, México.

LV Legislatura del Congreso del Estado de Campeche, 1994, “Decreto núm. 45”, promulgado por el Gobernador Constitucional del Estado, Jorge Salomón Azar García, en Periódico Oficial del Gobierno del Estado, 29 de diciembre, pp. 5-32.

Merino, Mauricio, 2009, "Los programas de subsidios al campo. Las razones y las sinrazones de una política mal diseñada", documento de trabajo 229, Centro de Investigación y Docencia Económicas, México. Disponible en línea: <http://repositorio-digital.cide.edu/bitstream/handle/11651/777/97145.pdf?sequence=1\&isAllowed=y>.

Paley, Julia, 2002, "Toward an Anthropology of Democracy", en Annual Review of Anthropology, vol. 31, pp. 469-496.

Poder Legislativo del Estado de Campeche, 2015, "Ley orgánica de los municipios del estado de Campeche”. Disponible en línea: <http:// www.ieec.org.mx/transparencia/doctos/art74/i/leyes/local/ley_organica_de_los_municipios_del_estado_de_campeche.pdf>. Consultado el 20 de octubre de 2018.

Tribuna de Campeche, 2006, "Falló la empresa, no los productores. Cierra Aceitera Campechana por ineficiencia”, 21 de mayo, p. 1.

Trouillot, Michel-Rolph, 2003, "The Anthropology of the State in the Age of Globalization: Close Encounters of the Deceptive Kind", en MichelRolph Trouillot, Global Transformations. Anthropology and the Modern World, Palgrave Macmillan, Nueva York, pp. 79-96.

Vadillo, Claudio, 2000, Campeche. Sociedad, economía, política, cultura, Universidad Nacional Autónoma de México, México. Warman, Arturo, 2004 [2001], El campo mexicano en el siglo xx, Fondo de Cultura Económica, México.

Zendejas, Sergio, 2003, Política local y formación del Estado. Procesos históricos de formación de espacios y sujetos sociales en un municipio rural mexicano, 1914-1998, tesis de doctorado, Wageningen Universiteit, Wageningen. 


\section{Entrevistas}

Adelfo Paul, Chicbul, 12 de marzo de 2003.

Gaudencio Camaal, Chicbul, 13 de junio de 2005. 